Article

\title{
Emergency Surgery in the Elderly: Could Laparoscopy Be Useful in Frailty? A Single-Center Prospective 2-Year Follow-Up in 120 Consecutive Patients
}

\author{
Monica Zese ${ }^{1, *}$, Elena Finotti ${ }^{2}$, Giovanni Cestaro ${ }^{1}$, Fabio Cavallo ${ }^{1}$, Daniela Prando ${ }^{1}$, Tobia Gobbi ${ }^{1}$, \\ Riccardo Zese ${ }^{3}(1)$, Salomone Di Saverio ${ }^{4,5}$ and Ferdinando Agresta ${ }^{1}$ \\ 1 Department of General Surgery, ULSS5 Polesana del Veneto, Santa Maria della Misericordia Hospital, \\ 45011 Adria, Italy; giovanni.cestaro@aulss5.veneto.it (G.C.); fabio.cavallo@aulss5.veneto.it (F.C.); \\ daniela.prando@aulss5.veneto.it (D.P.); tobia.gobbi@aulss5.veneto.it (T.G.); \\ ferdinando.agresta@aulss5.veneto.it (F.A.) \\ 2 Department of General Surgery, Ospedale Civile Santi Giovanni and Paolo, 30122 Venezia, Italy; \\ elena.finotti@live.it \\ 3 Department of Engineering, University of Ferrara, 44121 Ferrara, Italy; riccardo.zese@unife.it \\ 4 Cambridge University Hospitals, Cambridge CB2 0QQ, UK; salo75@inwind.it \\ 5 Department of Surgery, University of Insubria, 21100 Varese, Italy \\ * Correspondence: monica.zese@aulss5.veneto.it
}

\section{check for} updates

Citation: Zese, M.; Finotti, E.; Cestaro, G.; Cavallo, F.; Prando, D.; Gobbi, T.; Zese, R.; Di Saverio, S.; Agresta, F. Emergency Surgery in the Elderly: Could Laparoscopy Be Useful in Frailty? A Single-Center Prospective 2-Year Follow-Up in 120 Consecutive Patients. Surgeries 2021, 2, 119-127. https://doi.org/10.3390/ surgeries2010011

Academic Editor: Cornelis F.M. Sier

Received: 5 January 2021

Accepted: 10 March 2021

Published: 14 March 2021

Publisher's Note: MDPI stays neutral with regard to jurisdictional claims in published maps and institutional affiliations.

Copyright: (c) 2021 by the authors. Licensee MDPI, Basel, Switzerland. This article is an open access article distributed under the terms and conditions of the Creative Commons Attribution (CC BY) license (https:/ / creativecommons.org/licenses/by/ $4.0 /)$.

\begin{abstract}
Background: the general population is aging across the world. Therefore, even surgical interventions in the elderly-in particular those involving emergency surgical admissions-are becoming more frequent. The elderly population is often frail (in multiple physiological systems, this is often defined as age-related cumulative decline). This study involved a 2-year follow-up evaluation of frail elderly patients treated with urgent surgical intervention at Santa Maria Regina della Misericordia Hospital, General Surgery Department, in Adria (Italy). Method: a prospective, single-center, 2-year follow-up study of 120 patients $>65$ years old, treated at our department for surgical abdominal emergencies. We considered co-morbidities (ASA-American Society of Anesthesiologists Physical Status Classification System-score), type of surgery (laparoscopy, laparotomy or converted), frailty score, mortality, and complications at 30 days and at 2 years. Conclusions: $70(58.4 \%)$ patients had laparoscopy, $49(40.8)$ had laparotomy, and in $1(0.8 \%)$ case, surgery was converted from laparoscopy to laparotomy. Mortality strictly depends on the type of surgery (laparotomy vs. laparoscopy), complications during recovery, and a lower Fried frailty criteria score, on average. The long-term follow-up can be a useful tool to highlight a safer surgical approach, such as laparoscopy, in frail elderly patients. We consider the laparoscopic approach feasible in emergency situations, with similar or better outcomes than laparotomy, especially in frail elderly patients.
\end{abstract}

Keywords: laparoscopy; urgent surgery; elderly; frailty

\section{Aim}

The global population is aging [1]. The number of people worldwide $>65$ years of age is estimated to increase from 524 million in 2010 to 1.5 billion in 2050 . Consequently, the rate of surgical procedures in older populations is rising [2]. In the United States, 15\% of the population is $>65$ years of age, but this group accounts for $>35 \%$ of surgical operations. In Italy, according to the Italian National Institute for Statistics (Istituto Nazionale di Statistica, ISTAT), there were approximately 13.5 million people aged 65 and older in 2016 , representing $22.3 \%$ of inhabitants [3,4], and this value will continue to grow in the following years. Recovery, particularly for surgical emergencies, is considered complicated in the elderly [5-7], who tend to have longer hospital stays [7-9] (this is related to comorbidities, an elevated number of drugs taken, and reduced physical and mental reserves) $[3,5,8,9]$. Not all patients of the same age have the same risks or frailty issues (in 
multiple physiological systems, this is defined as age-related cumulative decline, and is considered a better predictor of mortality and morbidity than chronological age in the elderly). In the surgical field, the most frequent emergency diagnoses in the elderly are acute incarcerated hernia, cholecystitis, bowel obstruction and/or infarction, colic obstruction, and acute appendicitis [6]. Frailty assessment could facilitate identification of vulnerable surgical patients and, consequently, identify the appropriate surgical and anesthetic management [2]. However, currently there is no a standardized method of evaluation in emergency admissions [2,10]. Despite the urgent need for knowledge in treating elderly and/or frail surgical patients, especially in emergency situations, there are surprisingly few population-based studies [9,11-16] that involve long-term follow-ups. For this reason, our Santa Maria Regina della Misericordia Hospital, General Surgery Department, in Adria (Italy) participated in a study dubbed frailty and emergency surgery in the elderly: protocol of a prospective, multicenter study in Italy for evaluating perioperative outcome (FRAILESEL) [3]. Our evaluation started with a standardized evaluation of urgent admissions for surgical interventions in elderly, consequently we considered the Fried frailty score criteria at recovery. We followed-up at 30 days and at 2-years. Thus, this study was a prospective follow-up in the elderly ( $>65$ years of age). We considered patients treated with urgent surgical laparoscopy or laparotomy interventions at our Department, and evaluated Frailty Score criteria at the time of recovery, at 30 days, and at 2 years, regardless of comorbidities and type of surgical procedure.

\section{Methods}

This is a prospective observational single-center study that includes 120 consecutive patients over 65 years old, treated for surgical abdominal emergencies at our Department between July 2016 and October 2017 (totally 15 months), and enrolled during the FRAILESEL study period of enlistment. Inclusion criteria are patients $>65$ years of age, regardless of co-morbidities, and surgically treated for urgent-emergent abdominal pathology with laparoscopy or laparotomy. Exclusion criteria are patients $<65$ years of age and/or elective and re-operations. Every patient recovered has been surgically treated by our general surgeons. We followed-up patients for 2 years. Date of last contact was 31 October, 2019. Source data include co-morbidities, type of surgery (laparoscopy, laparotomy, or converted), length of stay, complications of surgery (Clavien Dindo classification [17]), and followup (at 30 days and at 2 years). We scanned our data with Perioperative Mortality Rate (POMR) [16] and the following Frailty Fried Scale criteria [18,19] (Figure 1): energy balance and nutrition (considering weight loss in the previous 3 months $>10 \%$ ), active mobilization (lowest quintile of kilocalories of physical activity during the past week), endurance (poor endurance and energy), weakness (hand grip strength in the lowest $20 \%$ quintile adjusted for sex and body mass index), slowness (walking speed under the lowest quintile adjusted for sex and height) at recovery and at 2 years (when possible). We compared these data with admittance diagnosis, (ASA - American Society of Anesthesiologists Physical Status Classification System - score) [20] complications, and mortality during hospitalization, at 30 days and at 2 years, to evaluate how frailty can impact in the follow up of urgent-emergency surgery admissions in elderly. We divided patients according to cause of death: medical or surgical complications during recovery and at 30 days, cardiovascular pathologies at 2 years, or the evolution of co-morbidities. We analyzed our data with statistical univariate analysis Chi-square, considering $p<0.05$ as significant value, and with linear regression, with $95 \%$ confidence interval, using SPSS Program ${ }^{\circledR}$ for Linux. 


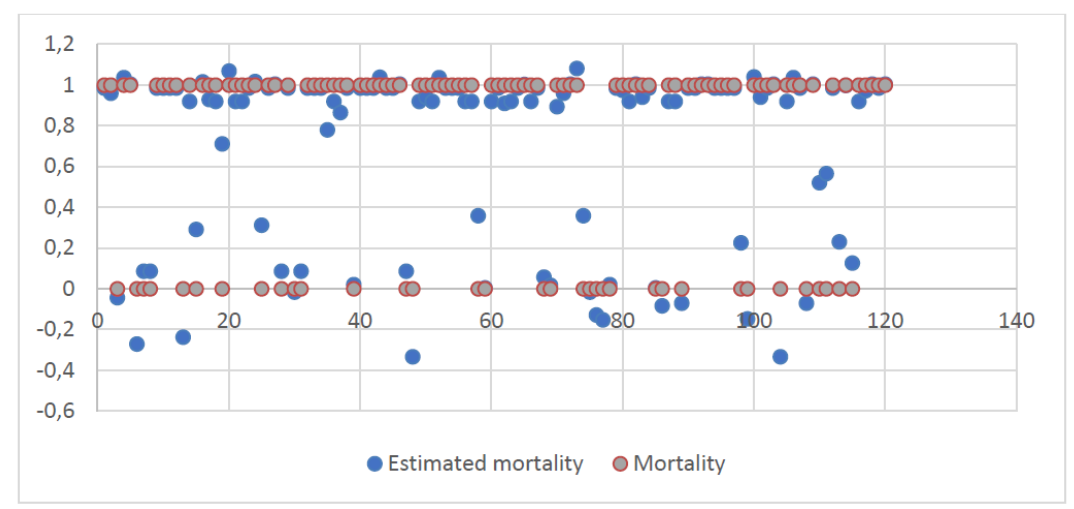

Figure 1. Results of linear regression between frailty criteria at recovery and after 2 years, and type of surgery, with estimated mortality.

\section{Results}

The study includes 120 patients (males $70,58.3 \%$, females 50, 41.7\%), average age 79 years old, (range $65-98$, median 79). Average BMI is $26.2 \mathrm{~kg} / \mathrm{m}^{2}$ (range $13-40 \mathrm{~kg} / \mathrm{m}^{2}$, median $25.313-40 \mathrm{~kg} / \mathrm{m}^{2}$ ). Median length of stay is 11 days (range 1-41, median 9). Comorbidities are presented in Table 1. ASA score is related to mortality $(p<0.0005): 22.5 \%$ of patients are ASA 3, 4.2\% are ASA 2, and $1.7 \%$ are ASA 4 . We admitted 43 patients with cholecystitis (35.8\%), 32 with colic obstruction (26.7\%), 19 with ileal obstruction or infarction (15.8\%), 13 with inguinal hernia obstruction (10.8\%), 10 with appendicitis $(8.4 \%)$, and 3 with incarcerated abdominal wall hernia $(2.5 \%)$. In $70(58.4 \%)$ cases, patients were treated with laparoscopic approach, in $49(40.8 \%)$ with laparotomic approach, and in $1(0.8 \%)$ case, surgery was converted from laparoscopy to open. In $4(3.3 \%)$ cases, an ileostomy was performed and in $12(10 \%)$ cases, a colostomy was made. During recovery, 6 patients died (5\%). At 2 years, $86(71.7 \%)$ patients were alive and $28(23.3 \%)$ dead: $24(70.6 \%)$ were males and $10(29.4 \%)$ females. Table 2 presents the causes of death for every ASA score, without finding a statistical connection, even considering relationship between cause of death and laparoscopic or open intervention (Table 3). We found intra-recovery complications in $19(15.8 \%)$ patients: 7 patients were treated with laparoscopic approach and 12 with open one (comparing the non-complicated approaches63 laparoscopic, 37 open, and 1 converted). So there is statistical relationship between mortality and laparotomic approach (Table 4 ) (respectively, $p<0.04$ and $p<0.03$ ). Therefore, mortality is linked to intrahospital complications, just as the laparoscopic approach has proven to be burdened by fewer complications and a lower mortality rate. Clavien Dindo Classification [17] and relationship with intra-recovery mortality is reported in Table 5. In Table 6, we relate abdominal surgery with type of surgery and total rate of mortality for the different surgeries. Laparoscopy is associated with lower mortality (Table 7) $(p<0.02)$. Frailty Score criteria at recovery (120 patients) and after 2 years (86 patients) are reported in Table 8 . The linear regression between frailty criteria at recovery and after 2 years, and type of surgery, with estimated mortality, shows a lower worsening of frailty rating in the elderly patient from hospitalization to 2 years $(p<0.0005)$. Considering linear regression, we analyzed the type of surgery and complications to estimate patient mortality with that predicted by the regression model $(R<0.009)$. The evaluation of Frailty criteria at recovery and after 2 years strictly shows correlation with mortality, real and estimated (Table 9, Figure 1). 
Table 1. Comorbidities.

\begin{tabular}{ccc}
\hline Co-Morbidities & $N$ & \% on 120 \\
\hline Heart attack $(<6$ months) & 1 & 0.8 \\
\hline Heart failure (<30 days) & 5 & 4.2 \\
\hline Chronic heart failure & 48 & 40 \\
\hline Previous coronary by-pass & 26 & 21.7 \\
\hline Hypertension & 93 & 77.5 \\
\hline Cerebrovascular diseases & 30 & 25 \\
\hline Peripheral chronic obstructive arterial disease & 18 & 15 \\
\hline Use of oral anticoagulant & 28 & 23.3 \\
\hline Pulmonary diseases & 26 & 21.7 \\
\hline Metastatic cancer & 6 & 5 \\
\hline Non-metastatic cancer & 21 & 17.5 \\
\hline Renal diseases & 20 & 16.7 \\
\hline Diabetes & 37 & 30.8 \\
\hline Use of immunosuppressant drugs & 8 & 6.7 \\
\hline Actual smoker & 8 & 6.7 \\
\hline Previous smoker & 37 & 30.8 \\
\hline
\end{tabular}

Table 2. Causes of death $(N)$, ASA score, $\%$ on total deaths and $\%$ on ASA score, and $p(0.05)$.

\begin{tabular}{|c|c|c|c|c|c|}
\hline Causes of Death & $N$ & $\%$ on 34 & ASA Score & $\%$ ASA Scores on 34 & $p(0.05)$ \\
\hline \multirow{4}{*}{ Medical/surgical during recovery } & \multirow{4}{*}{6} & \multirow{4}{*}{17.6} & ASA 1: 0 & 0 & \multirow{4}{*}{0.68} \\
\hline & & & ASA 2: 0 & 0 & \\
\hline & & & ASA 3: 5 & 14.7 & \\
\hline & & & ASA $4: 1$ & 2.9 & \\
\hline \multirow{4}{*}{ Medical/surgical $<30$ days } & \multirow{4}{*}{13} & \multirow{4}{*}{38.2} & ASA 1: 0 & 0 & \\
\hline & & & ASA 2: 5 & 14.7 & \\
\hline & & & ASA 3: 8 & 23.5 & \\
\hline & & & ASA 4: 0 & 0 & \\
\hline \multirow{4}{*}{ Cardiovascular diseases $<2$ years ${ }^{\infty}$} & \multirow{4}{*}{8} & \multirow{4}{*}{23.5} & ASA 1: 0 & 0 & \\
\hline & & & ASA 2: 0 & 0 & \\
\hline & & & ASA 3: 8 & 23.5 & \\
\hline & & & ASA 4: 0 & 0 & \\
\hline \multirow{4}{*}{ Evolution of comorbidities-other } & \multirow{4}{*}{7} & \multirow{4}{*}{20.7} & ASA 1: 0 & 0 & \\
\hline & & & ASA 2: 0 & 5.9 & \\
\hline & & & ASA 3: 6 & 17.6 & \\
\hline & & & ASA 4: 1 & 2.9 & \\
\hline
\end{tabular}

${ }^{\infty}$ in 2 cases cardiovascular diseases were not present at recovery.

Table 3. Causes of death $(\mathrm{N})$, type of surgery, $\%$ on total deaths (\% on 34), and $p(0.05)$.

\begin{tabular}{lccc}
\hline \multicolumn{1}{c}{ Causes of Death } & $\boldsymbol{N}$ & Type of Surgery (\% on 34) & $\boldsymbol{p ( 0 . 0 5 )}$ \\
\hline Medical/surgical during recovery & 6 & $\begin{array}{c}\text { Laparoscopic: } 0(0) \\
\text { Open: } 6(17.6) \\
\text { Converted: } 0(0)\end{array}$ & 0.5 \\
\hline Medical/surgical $<30$ days & 13 & $\begin{array}{c}\text { Laparoscopic: } 4(11.8) \\
\text { Open: } 8(23.5) \\
\text { Converted: } 1(2.9)\end{array}$ \\
\hline Cardiovascular diseases $<2$ years ${ }^{\infty}$ & 8 & $\begin{array}{c}\text { Laparoscopic: } 3(8.9) \\
\text { Open: } 5(14.7) \\
\text { Converted: } 0(0)\end{array}$ \\
\hline
\end{tabular}

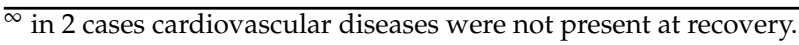


Table 4. Complications and their $\%$, mortality and its $\%$, type of surgery and its $\%$, and $p(0.05)$.

\begin{tabular}{|c|c|c|c|c|}
\hline Complications (\% on 120$)$ & Death (\% on 120$)$ & $p(0.05)$ & Type of Surgery (\% on 120) & $p(0.05)$ \\
\hline yes: 19 (15.8) & $9(7.5)$ & 0.04 & $\begin{array}{l}\text { Laparoscopic: } 7(5.8) \\
\text { Open: } 12(10) \\
\text { Converted: } 0(0)\end{array}$ & 0.03 \\
\hline no: 101 (84.2) & $25(20.8)$ & & $\begin{array}{c}\text { Laparoscopic: } 63(52.5) \\
\text { Open: } 37(30.9) \\
\text { Converted: } 1(0.8)\end{array}$ & \\
\hline
\end{tabular}

Table 5. Clavien Dindo Complications and their $\%$, mortality and its $\%$, and $p(0.05)$.

\begin{tabular}{cccc}
\hline Clavien Dindo & $\boldsymbol{N}$ (\% on 120) & Death $(\mathbf{\%}$ on 120) & $p$ (0.05) \\
\hline 1 & $4(3.3)$ & $0(0)$ & 0.8 \\
\hline 2 & $0(0)$ & $0(0)$ & \\
\hline $3 a$ & $3(2.5)$ & $1(0.8)$ & \\
\hline $3 \mathrm{~b}$ & $4(3.3)$ & $1(0.8)$ & \\
\hline $4 \mathrm{a}$ & $3(2.5)$ & $2(1.6)$ \\
\hline $4 \mathrm{~b}$ & $0(0)$ & $0(0)$ & \\
\hline 5 & $5(4.2)$ & $5(4.2)$ &
\end{tabular}

Table 6. Abdominal surgery $(N)$ and $\%$ on 120, type of surgery (\% on 120), mortality ( $\%$ on 120$)$, death in the different types of surgery (\% on 120$)$, and $p(0.05)$.

\begin{tabular}{|c|c|c|c|c|c|c|c|}
\hline $\begin{array}{l}\text { Abdominal } \\
\text { Surgery }\end{array}$ & $N(\%$ on 120$)$ & $\begin{array}{l}\text { Type of Surgery } \\
\quad(\% \text { on } 120)\end{array}$ & $p(0.05)$ & $\begin{array}{l}N \text { of Death } \\
(\% \text { on } 120)\end{array}$ & $p(0.05)$ & $\begin{array}{c}\text { Type of Surgery-Death } \\
(\% \text { on } 120)\end{array}$ & $p(0.05)$ \\
\hline Cholecystectomy & $43(35.8)$ & $\begin{array}{c}\text { Laparoscopic: } 41(34.2) \\
\text { Open: } 2(1.6) \\
\text { Converted: } 0(0)\end{array}$ & $<0.001$ & $7(5.8)$ & $<0.04$ & $\begin{array}{l}\text { Laparoscopic: } 6(5) \\
\text { Open: } 1(0.8) \\
\text { Converted: } 0(0)\end{array}$ & $<0.03$ \\
\hline Appendectomy & $10(8.4)$ & $\begin{array}{c}\text { Laparoscopic: } 9(7.5) \\
\text { Open: } 1(0.8) \\
\text { Converted: } 0(0)\end{array}$ & & $2(1.7)$ & & $\begin{array}{l}\text { Laparoscopic: } 2(1.7) \\
\text { Open: } 0(0) \\
\text { Converted: } 0(0)\end{array}$ & \\
\hline Ileal resection & $19(15.8)$ & $\begin{array}{l}\text { Laparoscopic: } 2 \text { (1.6) } \\
\text { Open: } 17(14.2) \\
\text { Converted: } 0(0)\end{array}$ & & $6(5)$ & & $\begin{array}{l}\text { Laparoscopic: } 0(0) \\
\text { Open: } 6(5) \\
\text { Converted: } 0(0)\end{array}$ & \\
\hline \multirow[t]{2}{*}{ Colic resection } & $32(26.7)$ & $\begin{array}{l}\text { Laparoscopic: } 15 \text { (12.5) } \\
\text { Open: } 16 \text { (13.3) }\end{array}$ & & $16(13.3)$ & & $\begin{array}{c}\text { Laparoscopic: } 6(5) \\
\text { Open: } 9 \text { (7.5) } \\
\text { Converted: } 1(0.8)\end{array}$ & \\
\hline & & Converted: $1(0.8)$ & & & & & \\
\hline $\begin{array}{l}\text { Inguinal hernia } \\
\text { reparation }\end{array}$ & $13(10.8)$ & $\begin{array}{c}\text { Laparoscopic: } 1(0.8) \\
\text { Open: } 12(10) \\
\text { Converted: } 0(0)\end{array}$ & & $3(2.5)$ & & $\begin{array}{c}\text { Laparoscopic: } 0(0) \\
\text { Open: } 3(2.5) \\
\text { Converted: } 0(0)\end{array}$ & \\
\hline $\begin{array}{c}\text { Incarcerated } \\
\text { abdominal wall } \\
\text { hernia reparation }\end{array}$ & $3(2.5)$ & $\begin{array}{c}\text { Laparoscopic: } 2(1.6) \\
\text { Open: } 1(0.8) \\
\text { Converted: } 0(0)\end{array}$ & & $0(0)$ & & $\begin{array}{c}\text { Laparoscopic: } 0(0) \\
\text { Open: } 0(0) \\
\text { Converted: } 0(0)\end{array}$ & \\
\hline
\end{tabular}

Table 7. Type of surgery (\% on 120$)$, mortality and $p(0.05)$.

\begin{tabular}{ccc}
\hline Type of Surgery & Mortality $N(\%$ on $\mathbf{1 2 0})$ & $p$ (0.05) \\
\hline Laparoscopy & $14(11.7)$ & 0.02 \\
\hline Open & $19(15.8)$ & \\
\hline Converted & $1(0.8)$ & \\
\hline
\end{tabular}


Table 8. Frailty score criteria at recovery ( $N 120$ and \% on 120), at 2 years ( $N 86$ and \% on 86), type of surgery at recovery (N 120 and \% on 120), at 2 years (N 86 and \% on 86) and $p(0.05)$.

\begin{tabular}{|c|c|c|c|c|c|}
\hline Frailty Score Criteria & $\begin{array}{c}\text { Weight Loss in the Previous } \\
3 \text { Months }(>10 \%)\end{array}$ & $\begin{array}{c}\text { Active } \\
\text { Mobilization }\end{array}$ & Endurance & Weakness & Slowness \\
\hline$N(120)$ at recovery (\% on 120$)$ & $4(3.3)$ & $71(59.2)$ & $17(14.2)$ & $22(18.3)$ & $112(93.3)$ \\
\hline $\mathrm{N}(86)$ at 2 years $(\%$ on 86$)$ & $8(9.3)$ & $60(69.8)$ & $10(11.6)$ & $22(25.6)$ & $85(98.9)$ \\
\hline$p(0.05)$ & 0.44 & & & & \\
\hline \multicolumn{6}{|l|}{ Type of surgery at recovery } \\
\hline Laparoscopy & $1(0.8)$ & $47(39.2)$ & $5(4.2)$ & $6(5)$ & $67(55.8)$ \\
\hline Laparotomy & $1(0.8)$ & $23(19.2)$ & $12(10)$ & $16(13.3)$ & $44(36.7)$ \\
\hline Converted & $0(0)$ & $1(0.8)$ & $0(0)$ & $0(0)$ & $1(0.8)$ \\
\hline \multicolumn{6}{|l|}{$\begin{array}{c}\text { Type of surgery } N(86) \text { at } \\
2 \text { years }(\% \text { on } 86)\end{array}$} \\
\hline Laparoscopy & $2(2.3)$ & $40(46.5)$ & $4(4.7)$ & $11(12.8)$ & $55(64)$ \\
\hline Laparotomy & $6(7)$ & $20(23.2)$ & $6(7)$ & $11(12.8)$ & $30(34.9)$ \\
\hline Converted & $0(0)$ & $0(0)$ & $0(0)$ & $0(0)$ & $0(0)$ \\
\hline$p(0.05)$ & 0.0005 & & & & \\
\hline
\end{tabular}

Table 9. Results of linear regression between frailty criteria at recovery and after 2 years, and type of surgery, with estimated mortality.

\begin{tabular}{cc}
\hline \multicolumn{3}{c}{ Statistical Regression } \\
\hline Multiple R & 0.950090474 \\
\hline $\mathrm{R}^{2}$ & 0.902671908 \\
\hline Adjusted $\mathrm{R}^{2}$ & 0.891756608 \\
\hline Standard error & 0.148876201 \\
\hline Observations & 120 \\
\hline
\end{tabular}

\section{Discussion}

In the early 2000s, Fried et al. [18,21] decided to re-define a concept that was introduced in the 1990s by Rockwood et al. [19,22], about frailty. Fried designated the so-called Frailty Phenotype, which used objective diagnostic criteria to define fragility, consequently differencing it from disability and co-morbidity. At this point, it became possible to identify different phenotypes: "frail" (with three or more criteria), "pre-frail" (one or two criteria), or "robust" (none of them). Therefore, it became feasible to rigorously differentiate, at least during the elective treatment of illnesses, frail elderly patients $[19,21,22]$. The majority of patients undergoing emergency laparotomy have potentially life-threatening conditions that require prompt investigation and treatment. Unlike elective surgery, there is often limited time to carry out investigations, especially in the elderly [23-27]. In literature [28-30], it is confirmed that older patients undergoing surgery have a higher risk of both mortality and complications compared to younger patients. An elevated ASA score and multiple co-morbidities increase mortality during post-operatory. ASA class 3 or higher predict a worse follow-up [9]. Moreover, hospitalization for older surgical patients is often complicated by physiologic decompensation, pre-existing co-morbidities, and prolonged length of stay [31,32]. These combined effects mean that aging populations pose new challenges for the dispensation of healthcare. In 2011, the National Emergency Laparotomy Audit (NELA), founded by NHS (National Health Service) England and the Welsh government, started collecting comparative information from all hospitals in England and Wales where emergency laparotomies were performed, to improve the care 
of patients. It was established in response to the comparatively high death rate after emergency laparotomy, and the substantial variation in this rate among hospitals [27]. Data from the fifth NELA report showed that $45 \%$ of emergency surgeries concerned patients $>75$ years, while in $55 \%$, the ASA score was $\geq 3$. Although NELA was created with the aim of comparing emergency laparotomies, the fifth report even considered bower emergent laparoscopy. It reports that the average mortality rate after emergency laparotomy remains static at $9.6 \%$ (in our study, it is about $15.8 \%$ ) and that $22.7 \%$ of patients do not have their preoperative mortality risk documented. NELA demonstrates that an assessment of frailty is not routinely performed. Frailty is associated with a greater risk of postoperative mortality and morbidity, which is independent of the risk associated with age. For patients over 65 , frailty assessment used alongside clinical risk assessment, plus specialist geriatric input for the older frail patients, is likely to improve their outcomes. Other studies confirm that for patients undergoing laparoscopic surgery, the 30 -day mortality is $3.5 \%$ compared to $10 \%$ via an open approach. The median length of stay for patients undergoing laparoscopic surgery is 6 days compared with 11 days for those who had an open emergency laparotomy [26,27]. Recent guidelines [33-36] recommend the laparoscopic approach in all patients, even in the elderly. A recent meta-analysis [37] shows that laparoscopy is associated with an earlier return to home with a satisfactory quality of life. In our study, and according to the literature [37-39], it is worthwhile to note that most emergency interventions are laparoscopic. According to the research in $[24,25]$, the use of supraglottic airway devices is also associated with a more rapid return to spontaneous breathing. This is obviously more feasible, considering a laparoscopic and less invasive approach. We can reasonably say that the laparoscopic approach is safer than the laparotomic one; this is true especially with a skilled surgical team. In references [23,26], the authors reported that, in the short term, results related to conversion from laparoscopy to laparotomy were not worse than the direct laparotomic approach. We just had one case, so we do not have a rating parameter. The only case that was converted (for an incarcerated hernia) died after 1 year because of a metastatic sigmoid cancer. Consequently, we cannot consider it significative. Our study is burdened with many biases. First, the comparison of different severities in surgical interventions (from low to high risk), and subsequently, the non-comparisons between comorbidities and type of surgery. We are also aware that most "major" surgeries have been set up with a laparotomic approach without attempting laparoscopy. This is related to individual surgical skills. Finally, we did not compare the baseline characteristic (age, comorbidities, frailty, and ASA score) of the two populations. We even decided to evaluate clinical observation at 2 years to verify the long-term effects of emergency surgery in the elderly, attempting to fill the gap present in the literature. The purpose of our study, with all of its limitations, is to focus on the need to systematically implement a frailty assessment in elderly patients, and attempt to increase the routine use of the laparoscopic approach, even in emergency surgeries in the elderly, as well as provide inspiration for improvement.

We agree with the literature $[2,17,28-31]$ that more research, regarding frailty and its impacts on surgical patients in acute settings, is needed. This tool must be efficient and suitable for application at the bedside, in every situation, and in daily moments. A more widespread application of the frailty score, in our opinion, can be useful in creating a longterm evaluative follow-up in frail patients; moreover, it can likely help with determining the right surgical approach for every patient (according to the skills of the operative surgical team). We must not only consider surgical intervention, but also anesthesiological intervention, using alternative procedures at intubation, such as supraglottic devices.

\section{Conclusions}

Our study could be a starting point to identify the most useful scores to establish, in a simple and rapid way, the risk classes of elderly and frail patients undergoing urgent surgery. We need the use of various criteria, and above all, a long follow-up that allows us to identify mortality and quality of life at a distance. Choosing the perfect surgery in the 
right patient is a great challenge. In fact, the NELA study began by only considering the laparotomy approach, while in subsequent reports, it opened its boundaries even to the most pioneering laparoscopy. Our study can be a starting point to study elderly patients in emergency settings, in its entirely (considering co-morbidities and fragility), at the recovery, and in the following years. We believe that a more logical approach to elderly patients can bring a more rational return to a satisfactory quality of life.

Author Contributions: Conceptualization, M.Z., E.F. and F.A.; methodology, D.P., F.C.; software, R.Z.; validation, M.Z., F.A., T.G. and S.D.S.; formal analysis, M.Z., R.Z.; E.F., G.C., resources, E.F., F.A., and S.D.S.; data curation, M.Z., R.Z.; writing—original draft preparation, M.Z., F.A.; and D.P., writing-review and editing, M.Z., F.A., and S.D.S.; visualization, F.C., G.C. and T.G.; supervision, D.P.; project administration, M.Z., F.A., S.D.S. All authors have read and agreed to the published version of the manuscript.

Funding: This research received no external funding.

Institutional Review Board Statement: The study was conducted according to the guidelines of the Declaration of Helsinki. It ia a Spin-off of Emergency Surgery in the Elderly: Comparison of Frailty Index and Surgical Risk Score (FRAILESEL) which is ClinicalTrials.gov Identifier: NCT02825082, 4252_2016-12/12/2016.

Informed Consent Statement: Informed consent was obtained from all subjects involved in the study.

Data Availability Statement: Data supporting are anonymous, preserved by the authors.

Conflicts of Interest: The authors declare no conflict of interest.

\section{References}

1. Christensen, K.; Doblhammer, G.; Rau, R.; Vaupel, J.W. Ageing populations: The challenges ahead. Lancet 2009, 374, 1196-1208. [CrossRef]

2. Lin, H.-S.; Watts, J.N.; Peel, N.M.; Hubbard, R.E. Frailty and post-operative outcomes in older surgical patients: A systematic review. BMC Geriatr. 2016, 16, 1-12. [CrossRef]

3. Costa, G.; Massa, G.; ERASO (Elderly Risk Assessment for Surgical Outcome) Collaborative Study Group. Frailty and emergency surgery in the elderly: Protocol of a prospective, multicenter study in Italy for evaluating perioperative outcome (The FRAILESEL Study). Updat. Surg. 2018, 70, 97-104. [CrossRef]

4. Istat: Stime per l'anno 2016.2017. Available online: https:/ / www.istat.it/it/archivio/197435 (accessed on 5 January 2021).

5. Jin, F.; Chung, F. Minimizing perioperative adverse events in the elderly. Br. J. Anaesth. 2001, 87, 608-624. [CrossRef]

6. Ukkonen, M.; Kivivuori, A.; Rantanen, T.; Paajanen, H. Emergency Abdominal Operations in the Elderly: A Multivariate Regression Analysis of 430 Consecutive Patients with Acute Abdomen. World J. Surg. 2015, 39, 2854-2861. [CrossRef] [PubMed]

7. Pelavski, A.D.; Lacasta, A.; Rochera, M.I.; De Miguel, M.; Roigé, J. Observational study of nonogenarians undergoing emergency, non-trauma surgery. Br. J. Anaesth. 2010, 106, 189-193. [CrossRef]

8. Centers for Disease Control and Prevention. Number of Discharges from Short-Stay Hospitals, by First-Listed Diagnosis and Age: United States. 2010. Available online: www.cdc.gov/nchs/data/nhds/3firstlisted/2010first3_numberage.pdf (accessed on 7 July 2019).

9. Miettinen, P.; Pasanen, P.; Salonen, A.; Lahtinen, J.; Alhava, E. The outcome of elderly patients after operation for acute abdomen. Ann. Chir. Gynaecol. 1996, 85, 11-15.

10. de Vries, N.M.; Staal, J.B.; Van Ravensberg, C.D.; Hobbelen, J.S.; Rikkert, M.O.; Nijhuis-Van der Sanden, M.W. Outcome instruments to measure frailty: A systematic review. Ageing Res. Rev. 2011, 10, 104-114. [CrossRef]

11. Chua, M.S.; Chan, D.K. Increased morbidity and mortality of emergency laparotomy in elderly patients. World J. Surg. 2020, 44 , 711-720. [CrossRef] [PubMed]

12. Bentrem, D.J.; Cohen, M.E.; Hynes, D.M.; Ko, C.Y.; Bilimoria, K.Y. Identification of Specific Quality Improvement Opportunities for the Elderly Undergoing Gastrointestinal Surgery. Arch. Surg. 2009, 144, 1013-1020. [CrossRef] [PubMed]

13. McGillicuddy, E.A.; Schuster, K.M.; Davis, K.A.; Longo, W.E. Factors Predicting Morbidity and Mortality in Emergency Colorectal Procedures in Elderly Patients. Arch. Surg. 2009, 144, 1157-1162. [CrossRef] [PubMed]

14. Rigberg, D.; Cole, M.; Hiyama, D.; McFadden, D. Surgery in the nineties. Am. Surg. 2000, 66, 813.

15. Iversen, L.H.; Bülow, S.; Christensen, I.J.; Laurberg, S.; Harling, H.; On behalf of the Danish Colorectal Cancer Group. Postoperative medical complications are the main cause of early death after emergency surgery for colonic cancer. BJS 2008, 95, 1012-1019. [CrossRef]

16. Watters, D.A.; Hollands, M.J.; Gruen, R.L.; Maoate, K.; Perndt, H.; McDougall, R.J.; Morriss, W.W.; Tangi, V.; Casey, K.M.; McQueen, K.A. Perioperative Mortality Rate (POMR): A Global Indicator of Access to Safe Surgery and Anaesthesia. World J. Surg. 2015, 39, 856-864. [CrossRef] 
17. Dindo, D.; Demartines, N.; Clavien, P.A. Classification of surgical complications: A new proposal with evaluation in a cohort of 6336 patients and results of a survey. Ann. Surg. 2004, 240, 205. [CrossRef]

18. García-García, F.J.; Carcaillon, L.; Fernandez-Tresguerres, J.; Alfaro, A.; Larrion, J.L.; Castillo, C.; Rodriguez-Mañas, L. A New Operational Definition of Frailty: The Frailty Trait Scale. J. Am. Med. Dir. Assoc. 2014, 15, 371.e7-371.e13. [CrossRef]

19. Rockwood, K.; Stadnyk, K.; MacKnight, C.; McDowell, I.; Hébert, R.; Hogan, D.B. A brief clinical instrument to classify frailty in elderly people. Lancet 1999, 353, 205-206. [CrossRef]

20. Mayhew, D.; Mendonca, V.; Murthy, B.V. A review of ASA physical status-historical perspectives and modern developments. Anaesthesia 2019, 74, 373-379. [CrossRef]

21. Fried, L.P.; Tangen, C.M.; Walston, J.; Newman, A.B.; Hirsch, C.; Gottdiener, J.; Seeman, T.; Tracy, R.; Kop, W.J.; Burke, G.; et al. Frailty in Older Adults: Evidence for a Phenotype. J. Gerontol. Ser. A Biol. Sci. Med. Sci. 2001, 56, M146-M156. [CrossRef] [PubMed]

22. Rockwood, K.A.; Fox, R.; Stolee, P.; Robertson, D.; Beattie, B.L. Frailty in elderly people: An evolving concept. Can. Med Assoc. J. 1994, 150, 489-495.

23. Agresta, F.; Piazza, A.; Michelet, I.; Bedin, N.; Sartori, C.A. Emergency laparoscopic surgery: A hospital's experience. Minerva Chir. 1999, 54, 559-564.

24. Yoon, S.W.; Kang, H.; Choi, G.J.; Ryu, C.; Park, Y.H.; Baek, C.W.; Jung, Y.H.; Woo, Y.C. Comparison of supraglottic airway devices in laparoscopic surgeries: A network meta-analysis. J. Clin. Anesthesia 2019, 55, 52-66. [CrossRef] [PubMed]

25. Ruetzler, K.; Guzzella, S.E.; Tscholl, D.W.; Restin, T.; Cribari, M.; Turan, A.; You, J.; Sessler, D.I.; Seifert, B.; Gaszynski, T.; et al. Blind Intubation through Self-pressurized, Disposable Supraglottic Airway Laryngeal Intubation Masks. Anesthesiology 2017, 127, 307-316. [CrossRef] [PubMed]

26. NELA project team. The First Patient Report of the National Emergency Laparotomy Audit; RCoA: London, UK, 2015.

27. Boyd-Carson, H.; Doleman, B.; Herrod, P.J.J.; Anderson, I.D.; Williams, J.P.; Lund, J.N.; Tierney, G.M.; Murray, D.; Hare, S.; Lockwood, S.; et al. Association between surgeon special interest and mortality after emergency laparotomy. BJS 2019, 106, 940-948. [CrossRef]

28. Joseph, B.; Zangbar, B.; Pandit, V.; Fain, M.; Mohler, M.J.; Kulvatunyou, N.; Jokar, T.O.; O'Keeffe, T.; Friese, R.S.; Rhee, P. Emergency General Surgery in the Elderly: Too Old or Too Frail? J. Am. Coll. Surg. 2016, 222, 805-813. [CrossRef] [PubMed]

29. Kim, S.-W.; Han, H.-S.; Jung, H.-W.; Kim, K.-I.; Hwang, D.W.; Kang, S.-B.; Kim, C.-H. Multidimensional Frailty Score for the Prediction of Postoperative Mortality Risk. JAMA Surg. 2014, 149, 633-640. [CrossRef]

30. Joseph, B.; Zangbar, B.; Pandit, V.; Kulvatunyou, N.; Haider, A.; O’Keeffe, T.; Khalil, M.; Tang, A.; Vercruysse, G.; Gries, L.; et al. Mortality after trauma laparotomy in geriatric patients. J. Surg. Res. 2014, 190, 662-666. [CrossRef] [PubMed]

31. Shah, A.A.; Haider, A.H.; Riviello, R.; Zogg, C.K.; Zafar, S.N.; Latif, A.; Diaz, A.J.R.; Rehman, Z.; Zafar, H. Geriatric emergency general surgery: Survival and outcomes in a low-middle income country. Surgery 2015, 158, 562-569. [CrossRef]

32. Etzioni, D.A.; Liu, J.H.; Maggard, M.A.; Ko, C.Y. The Aging Population and Its Impact on the Surgery Workforce. Ann. Surg. 2003, 238, 170-177. [CrossRef]

33. Fugazzola, P.; Ceresoli, M.; Agnoletti, V.; Agresta, F.; Amato, B.; Carcoforo, P.; Catena, F.; Chiara, O.; Chiarugi, M.; Cobianchi, L.; et al. The SIFIPAC/WSES/SICG/SIMEU guidelines for diagnosis and treatment of acute appendicitis in the elderly (2019 edition). World J. Emerg. Surg. 2020, 15, 1-15. [CrossRef]

34. Sartelli, M.; Catena, F.; Ansaloni, L.; Coccolini, F.; Griffiths, E.A.; Abu-Zidan, F.M.; Di Saverio, S.; Ulrych, J.; Kluger, Y.; Ben-Ishay, O.; et al. WSES Guidelines for the management of acute left sided colonic diverticulitis in the emergency setting. World J. Emerg. Surg. 2016, 11, 1-5. [CrossRef] [PubMed]

35. Birindelli, A.; Sartelli, M.; Di Saverio, S.; Coccolini, F.; Ansaloni, L.; van Ramshorst, G.H.; Campanelli, G.; Khokha, V.; Moore, E.E.; Peitzman, A.; et al. 2017 update of the WSES guidelines for emergency repair of complicated abdominal wall hernias. World J. Emerg. Surg. 2017, 12, 1-6. [CrossRef] [PubMed]

36. Di Saverio, S.; Birindelli, A.; Kelly, M.D.; Catena, F.; Weber, D.G.; Sartelli, M.; Sugrue, M.; De Moya, M.; Gomes, C.A.; Bhangu, A.; et al. WSES Jerusalem guidelines for diagnosis and treatment of acute appendicitis. World J. Emerg. Surg. 2016, 11, 34. [CrossRef]

37. Liu, Z.; Zhang, P.; Ma, Y.; Chen, H.; Zhou, Y.; Zhang, M.; Chu, Z.; Qin, H. Laparoscopy or not. Surg. Laparosc. Endosc. Percutaneous Tech. 2010, 20, 362-370. [CrossRef]

38. Kettunen, J.; Paajanen, H.; Kostiainen, S. Emergency abdominal surgery in the elderly. Hepatogastroenterology 1995, $42,106-108$.

39. Caglià, P.; Tracia, A.; Buffone, A.; Amodeo, L.; Tracia, L.; Amodeo, C.; Veroux, M. Physiopathology and clinical considerations of laparoscopic surgery in the elderly. Int. J. Surg. 2016, 33, S97-S102. [CrossRef] [PubMed] 